Voice source changes of child and adolescent subjects undergoing singing training - a preliminary study.

C.A.Barlow and D.M.Howard

Department of Electronics

University of York,

Heslington, York,

UK

YO10 5DD

Contact: Mr C.A.Barlow

Music Technology Research Group

Department of Electronics

University of York, Heslington,

York, UK

Tel: +44 (0)1904 432407

Email: cab124@york.ac.uk

Paper presented at PEVOC IV August 2001 


\title{
Voice source changes of child and adolescent subjects undergoing singing training - a preliminary study
}

\author{
Logopedics Phoniatrics Vocology \\ C.A.Barlow and D.M.Howard \\ University of York, UK.
}

\begin{abstract}
Many vocal practitioners have strong beliefs regarding the age at which singing training of a child should begin, and the different ways in which male and female children should be treated. These beliefs are not substantiated by any scientific research, leading to considerable dispute between vocal coaches and choral directors.

The singing voices of over 127 child singers and non singers aged 8-18 were analysed using Electrolaryngographic measures. Analysis particularly concentrated on the laryngographically derived vocal fold closed quotient (CQ).

Results indicated that the voice source characteristics of subjects could be divided into groups according to age, gender and the level of vocal training received. Female subjects in particular exhibited a marked development of voice source production according to the length of training received, while male subjects exhibited patterning according to both age (and related pubertal development), and training received. It was concluded that the process of training a young voice has a quantifiable effect upon the singing voice production of the child, and in particular on the female voice, while pubertal development also creates measurable effects on the voice source production of the male child.
\end{abstract}

Keywords: Electrolaryngography, Singing, Closed Quotient, Adolescent, Voice change. 


\section{Introduction}

Over recent years a number of researchers have attempted to provide a quantifiable analysis of the effect upon the adult singing voice of formal vocal training. The results of a number of these studies appear to indicate that formal training in singing has a measurable effect upon vocal production, particularly at the voice source. It has been further indicated that such analysis when used in a biofeedback device could provide a training tool which can increase the rate at which singers improve their vocal technique [19].

By far the greatest amount of analysis of singers has been performed upon adult, usually classically trained (in what is often known as the 'bel canto' style) performers, with some work having been undertaken with 'belt' style singers. Remarkably little work has studied the effect of formal training upon children and younger teenagers, whose voices are still in the process of developing.

\section{Background}

In the UK, there are 40 Anglican (Episcopal) cathedrals, each of which maintains the traditional pattern of choral worship, in which a considerable part of the service is set to music and sung by the Cathedral Choir. The choir usually sings two to three services on a Sunday, as well as at least one service per day every weekday. In these choirs the Bass and Tenor lines are sung by adult, professional male singers, and the alto line is in most cases also made up of adult male counter-tenors. With little exception, the soprano (or 'treble') line of the choir is sung by children.

This tradition has been maintained for hundreds of years - for example the choir school at York Minster can date its antecedents back to 627AD. For most of this period the treble line has been sung by boy trebles, but in recent years a number of cathedrals have admitted girl choirs as well as the traditional boy choirs. These 
singers, despite their age, are 'professional' in every sense of the word. They sing six days a week with a professional conductor, performing 'live' on most of those days, with a rapidly changing repertoire, in addition to which they perform on radio broadcasts, concert tours and recordings. In return for this, the choristers usually receive scholarships towards the cost of fees at the choirschool, most of which are specialist music schools, providing tuition in a number of musical instruments as well as voice training.

In addition to cathedral choristers, a large number of other children also train their voices with professional teachers. While singing in state schools has drastically decreased in recent years some schools still maintain excellent choirs. Many private schools also specialise in music tuition and singing is still considered to be an excellent way to develop musicianship skills.

\section{[insert figure 1]}

Despite this tradition of child singers, there are many schools of thought as to how singing tuition should be approached for child singers. A child's vocal system undergoes rapid and dramatic change during adolescence, during which many singers are making demands on their voice as great as that of any adult. During the pubertal growth spurt, both male and female larynxes change dimensions rapidly (figure 1), necessitating a constant reassertion of the muscle control skills needed for speech and singing. There are as many conflicting ideas on how child singers should be treated during this period as there are vocal pedagogues who deal with child singers. In spite of this, there has been very little research undertaken to attempt to determine the effect of regular singing and vocal training on the voice production of children and adolescents. 
This paper explores a pilot study aimed at providing some quantifiable data regarding the effect of training and regular singing on the voice source of young singers, aged 8-18.

\section{Methodology}

Electrolaryngography uses the measurement of electrical impedance to give a direct, noninvasive measurement of laryngeal activity. It is widely used for $F_{0}$ estimation in laboratories and clinics [11].

Human tissue is a moderately good conductor of electricity, and the electrolaryngograph uses a constant voltage high frequency electric current passed between two electrodes placed externally either side of the neck at the level of the larynx. The output waveform (Lx) (figure 2) represents the current flowing between the electrodes. When the vocal folds are apart, the current must flow along a longer path between the electrodes, increasing impedance of the signal. The current will thus be higher when the vocal folds are in contact than when they are apart. The current variation can therefore be analysed in terms of changes in vocal fold contact area. [1]: 281.

\section{[Insert figure 2]}

The opening and closing of the folds can be divided into two phases; Closed Phase (CP) and Open Phase (OP). [12] The length of the cycle (waveform period) is known as Tx. The percentage of the cycle for which the vocal folds are in contact is known as the 'larynx closed quotient' or CQ, which is found as:

$$
\mathrm{CQ}=[\mathrm{CP} / \mathrm{Tx}] * 100 \%
$$

As the wave period (Tx) is calculated, the Lx waveform can also be used to derive real time $\mathrm{F}_{0}$ estimation. As the waveform is relatively immune to external acoustic 
factors, it can provide a useful alternative to acoustic measures of $F_{0}$ such as peakpicking.

The electroglottograph (EGG) output waveform is essentially similar to the Lx output waveform, although it is usually plotted as the inverse. Comparison of data from EGG and Lx analyses is therefore legitimate, assuming that the polarity is taken into account. Baken [3], Fourcin/Abberton [8] and Howard [15] give detailed reviews of EGG and electrolaryngograph operation.

\section{Subjects and Data analysis}

76 Female and 51 Male young singers and non-singers from 11 schools took part in the study. These included choristers from 7 Cathedral Choirschools around Britain, in addition to which further subjects were taken from three schools specialising in music, and one non-specialist school. All except 4 subjects were White European, the exceptions being three subjects of Asian extraction and one subject of AfricanAmerican extraction. Each subject was recorded by the researchers in the songschool or music department of their school. The youngest subjects recorded were at least 8 years old, and the eldest not more than 18 . The 11 schools were visited over a period of 1.5 years between February 2000 and July 2001.

Subjects indicated whether or not they were a 'singer' or a 'non-singer', and if a singer the length of time they had been training their voice. For the purposes of this study, 'singers' were considered to be those who undertake regular individual formal singing training with a professional coach/singing teacher, or who sang at least twice per week in a group environment with a professional singing coach or choral director. (This does not include school choirs). This information was confirmed by the choirmaster or music teacher of the children. Subjects were also asked their date of birth as a developmental indicator. 
The subjects voices were recorded a) reading aloud a passage of spoken text approximately 90 s in duration and b) singing a 2 octave scale to the vowel of /a/ covering the pitch range of $\mathrm{G}$ major. The spoken text was a section of 'Arthur the Rat', which has been used in a number of similar studies. In the case of females or boy trebles the scale was sung from G3 $(196 \mathrm{~Hz})$ to G5 $(784 \mathrm{~Hz})$. In the case of changed male voices, the scale was sung from G2 $(98 \mathrm{~Hz})$ to $\mathrm{G} 4(392 \mathrm{~Hz})$, or as near to G4 as the subject could reach. Subjects were asked to project the sound at as consistent a level as possible, 'as if they were singing a solo'. They were not required to sing the entire scale in one breath, but asked to breathe when necessary to maintain as regular a volume as possible. In the event of a subject running out of breath whilst singing, the subject was asked to repeat the scale.

The output waveform from an electrolaryngograph (Lx) and the speech pressure waveform ( $\mathrm{Sp}$ ) from an AKG CK77 omnidirectional condensor microphone were recorded onto the two channels of a Fostex DA-5 DAT (Digital Audio Tape) recorder. The microphone was powered by a Mackie 1402 VLZ-PRO low noise mixer. The Lx signal was viewed on an oscilloscope during the recording to maintain correct electrode positioning.

Data analysis was undertaken using the Speech Studio ${ }^{\mathrm{TM}}$ and Quantitative Analysis ${ }^{\mathrm{TM}}$ software running on a PC with PIII $450 \mathrm{~Hz}$ processor fitted with the Laryngograph ${ }^{\mathrm{TM}}$ [23] processor card. The recordings were digitally transferred to the PC for storage and analysis.

The Speech Studio software was used to output a text file of sample number, derived $\mathrm{F}_{0}$, and CQ for each subject, which was then analysed in a spreadsheet. Quantitative Analysis $^{\mathrm{TM}}$ was used to plot scattergrams of $\mathrm{CQ} / \log \mathrm{F} 0$ for visual analysis. 


\section{Results}

For the purposes of this study, the spoken text was used to return only the mean speaking pitch of each subject as a further developmental indicator in addition to the recorded age.

The data for the sung scale was plotted for each subject as a $C Q / \log F_{0}(Q x)$ scattergram. This plot allows a visual analysis of the general trend of CQ against changing pitch. (Figure 3)

\section{[insert figure 3]}

$\mathrm{CQ} / \log \mathrm{F}_{0}$ trend analysis

Each of the Qx scattergrams was analysed and the pattern of the slope noted (positive, negative or neutral gradient, and the point of any gradient change). These results were recorded in a database containing age, training and gender information. This was then analysed for trends amongst particular demographic groups.

\section{Subjects 12 years of age and under}

The development of the larynx in both male and female children occurs about 6 months after pubertal onset, about age 11.5 years in female children, and 12 years in male children [20]. The cartilage growth which triggers the larynx development is part of the general 'growth spurt' which occurs in adolescents during puberty. Children aged 12 or under can therefore normally be assumed to be vocally either prepubescent or in the early stages of adolescence (Sex Maturity Rating 1-2) , as indicated by Tanner [20]. The voice classification index developed by Gackle [9] indicates that female subjects in this age group will be in either Stage I (Prepubertal) or Stage IIA (Pre-Menarcheal). Larynx development will begin to occur in some subjects, but will be in its early stages. This means that laryngeal dimensions will vary by only a small amount for this age group. For this reason subjects aged 12 
years and under were analysed as a single group. A further indicator that the male subjects of this age range are prepubescent is that all subjects are singing in the 'treble' (soprano) register, rather than tenor or baritone registers. Of the children analysed, none of the male subjects aged 12 or under had undergone voice change. On analysing the Qx plots, it was found that they fell into 5 general categories according to the gradient of the best fit line.

The plots were grouped according to the variation in slope patterns. These divided into discrete groups depending on whether the gradient was positive or negative, and how many changes in gradient occurred. (Table 1).

\section{[insert Table 1]}

\section{Non-singers}

The results of this analysis demonstrated that both male and female non-singers trend towards the Group 1 pattern (constant negative gradient), with the female sample group showing considerably less variation than the male (table 2). There is a near $73 \%$ instance of group 1 patterns for the female group and $55 \%$ for the male, with the next highest instance in either group being $18 \%$.

\section{[insert Table 2]}

\section{Singers}

Analysis of the results of the trained singers in the 12 and under age group demonstrates that some patterning occurs with increased levels of singing training. The female group in particular has a very strong correlation between the mean length of training and the particular Qx pattern being exhibited by a group of singers (table 3). The male group, while the correlation is not as strong, still indicates some sign that increased training changes vocal production according to a reasonably regular pattern. Groups 2-4 in the male group demonstrate a change in pattern with increased training that corresponds closely to the female singers. Only one subject 
demonstrated the group 5 plot, so could possibly be anomalistic, as he had only been training for 1.5 years, considerably less than would otherwise be expected for this plot type. (Barlow, 1999, Howard, 1995).

\section{[insert table 3]}

\section{Subjects $13+$ years of age}

Subjects of 13 or more years of age will vary in pubertal development according to both age and genetic traits. While the pubertal onset is usually about 11.5 years of age, it can occur earlier or later than that. This being said, most children will have reached SMR stage 3 (mid-puberty) by the age of 13, and SMR 4 (late puberty) by age 15. By the age of 18, most subjects will be at SMR 5, having full adult growth and characteristics.

Over this period from 13-18 years of age, both male and female children undergo dramatic changes in their vocal tract, which could have implications for the production of the voice. The Qx plots of subjects were analysed in terms of age and mean speaking $\mathrm{F}_{0}$ for indicators of pubertal development, as well as duration of voice training.

\section{Female Singers}

The female singers in the sample demonstrated very similar patterns to the younger group of female singers (table 4). While the subjects exhibiting group 1 patterns has a mean duration of training slightly higher than that of group 2, groups 2-5 show a progression through the plots that is again a close correlation between pattern and mean duration of training. Furthermore, the training levels of the groups are remarkably close to those of the same groups in the younger age group.

There is no indication that age or mean speaking frequency are significant in this patterning, as there is no clear trend shown by either of these measures. 


\section{[insert Table 4]}

\section{Female non-singers}

This group again demonstrates a strong inclination towards the group 1 pattern (55\%), with group 2 at $31 \%$ and the others insignificant (table 5). The indication from this would appear to be that untrained voices generally exhibit a decreasing CQ with increased $\mathrm{F}_{0}$.

\section{[insert Table 5]}

\section{Male subjects}

The male subjects in the over 13 age group demonstrated a very different patterning from the other groups. Whereas the other groups appear to show the shape of the Qx plot to be primarily a function of the level of training received by the subject, the indications for male adolescents appear to demonstrate a function of age (and therefore presumably of physical development).

While there were 3 apparent patterns of Qx in the male adolescent category, the small sample number means that these patterns are not conclusive. However, from the available data, patterns for adolescent males are suggested as follows (table 6):

\section{[insert Table 6]}

Pubertal and Post pubertal (changed voice) male subjects did not demonstrate any correlation of the pattern of their Qx plot and the level of singing training that they had received. (Table 7). There is some indication, however, that the pattern of the Qx plot gradually flattens during the pubertal process, and that the Qx plot of subjects flattens out (little or no change in CQ with changed $\mathrm{F}_{0}$ ) as they complete puberty and reach adult maturity.

\section{[insert table 7]}


The subjects analysed as group 1 all exhibited a downward sloping plot. The mean speaking frequency of these subjects is $171 \mathrm{~Hz}$, and therefore still considerably higher than mean adult speaking $\mathrm{F}_{0}$. The pitch range of the sung scale of these subjects was found to vary between D3 and E5. None of the subjects could attain the highest notes of the treble scale (F5, G5), or the lower notes of the bass/tenor scale (G2-C3). This suggests that while vocal change has started, the subjects are still vocally only in early pubescence, and therefore are likely to still follow the patterns of prepubescent subjects. As these subjects have not reached adult speaking pitch, and exhibit a plot typical of untrained prepubescent subjects, it is suggested that if a larger sample of this age group were obtained, the Qx plots of subjects in will vary according to training levels according to table 4 above. These suggestions will, however, need extensive testing before they can be presented as conclusive.

The other three groups all exhibit values close to adult speaking pitch. Group 4 contains by far the highest proportion of the subjects in the sample group, and further analysis of the subjects indicates that this pattern is evenly divided between trained singers - the most experienced of whom had been training for nearly 8 years - and non-singers. Given that the mean age of the subjects is the highest of all the group, this suggests that the 'horizontal' or 'flat' Qx plot in which CQ remains constant with changing $\mathrm{F}_{0}$ is achieved as male subjects reach adult maturity. This correlates with results demonstrated in a previous study [12], in which adult male singers all exhibited Qx plots with little variation in $\mathrm{CQ}$ with varying $\mathrm{F}_{0}$, although mean $\mathrm{CQ}$ varied with increased training.

Indications from groups 2 and three are less evident. While subjects in group 2 have a higher mean age than those in group 3, subjects in group 3 have a lower speaking pitch, indicating more advanced pubertal development. Their numerical 
ordering is therefore arbitrary, and should not suggest that these patterns necessarily occur in that order. Again, due to the sample size, further research needs to be conducted before this grouping can be presented as conclusive.

\section{Conclusion}

Results from this study indicate that voice source production of children changes in a predictable and measurable pattern with increased vocal training for prepubescent male and female children, and also for adolescent females. The vocal production of adolescent males appears to change in a regular pattern as a function of pubertal development. The rapid nature of this change means that it is difficult to tell the effect, if any, that training levels have upon this process.

For the prepubertal male and all female subjects the similarity to the patterning demonstrated by adult female singers is significant. [15] (figure 6). It can be suggested from this that training a child's voice is likely to result in improved technique of at least voice production at source. There was no indication in the study that the subjects who trained their voices professionally from an early age had suffered as a result. The small change in the female larynx during the pubertal growth period was insufficient to cause any dramatic change in vocal production, and so there appears to be no reason why female singers should not continue training from childhood to adulthood.

\section{[insert figure 6]}

The results of this study cannot infer whether or not training a male voice through adolescence is beneficial, as the data is inconclusive.

Figures 4 and 5 show idealised Qx plots for male and female child and adolescent singers which have been derived from this study:

\section{[Insert figure 4]}




\section{[insert figure 5]}

\section{Future work}

While this study has demonstrated that there is a measurable change in voice source production as a factor of training and pubertal development, in order for this data to be useful it will be necessary to undertake further study. Areas identified for further study are as follows:

1. Longitudinal study of a number of subjects over a period of time in order to characterise the effect of training on a single voice over time, and with relation to specific developmental characteristics.

2. Investigate the effect of training on adolescent males using a greater sample number and more developmental indicators (height, weight, shoulder width) to determine whether or not training is effective on the male changing voice.

3. Analyse numerical data for CQ values against frequency for more accurate quantisation of voice production characteristics.

\section{Acknowledgements}

This study would have not been possible without the cooperation and assistance of many people. Particular thanks go to:

Neil Taylor, Master of the Music, Sheffield Cathedral.

Tony Jones, Head of Music, High Storrs School, Sheffield

Richard Shepherd, Headmaster, York Minster School, Philip Moore, Master of the Music, York Minster

Simon Lole, Master of the Music, Salisbury Cathedral, Richard Moore, Headmaster, Ripon Cathedral Choirschool, Stewart Smith, Head of Music, Abbey Gate College, Chester 
Phyl Barlow, Abbey Gate School, Chester

Matthew Owens, Master of the Music, Edinburgh Episcopal Cathedral

Malcom Archer, Master of the Music, Wells Cathedral

Richard Tanner, Master of the Music, Blackburn Cathedral,

Alasdair Jamieson, Head of Music, Bootham School, York

\section{Bibliography}

1. Abberton, E.R., Howard, D.M., Fourcin, A.J. (1989), Laryngographic assessment of normal voice: a tutorial. Clinical Linguistics and Phonetics, 3, 281,296.

2. Andrews, M.L., (1993). Intervention with young voice users: A clinical perspective. Journal of Voice, 7, 160-164

3. Baken, R.J., (1987). Clinical Measurement of Speech and Voice. Boston: College Hill.

4. Barlow, C.A., (1999) The developing voice from child to adult - a laryngographic analysis. Unpublished MSc dissertation, University of York, UK.

5. Childers, D.G., Hicks, D.M., Moore, G.P., Alsaka, Y.A., (1986). A model for vocal fold vibratory motion, contact area, and the electrolaryngogram. Journal of the Acoustical Society of America. 80:1309-1320.

6. Cooksey, J.M., (1993). Do adolescent voices 'break' or do they 'transform'? Voice, 2, $15-39$.

7. Evans, M., Howard, D.M., (1993). Larynx closed quotient in female belt and opera qualities: a case study. Voice, 2, 7-14.

8. Fourcin, A.J., Abberton, E.R.M., (1971) First Applications of a new Laryngograph. Medical and Biological Review, 21, 172-182. 
9. Gackle, M.L. (1991). The Adolescent Female Voice: Characteristics of change and stages of development. The Choral Journal, 31(8):17-25.

10. Garner, P.E., Howard, D.M., (1999). Real-time display of voice source characteristics. Logopedics Phoniatrics Vocology, 24, 19-25.

11. Gilbert, H.R., Potter, C.R., Hoodin, R., (1984). The laryngograph as a measure of vocal fold contact area. Journal of Speech and Hearing Research, 27, 178-182.

12. Howard, D.M., Lindsey, G.A., Allen, B., (1990a). Towards the quantification of vocal efficiency. Journal of Voice, 4, 205-212.

13. Howard, D.M. (1992) Quantifiable aspects of different singing styles. Voice, 1, 47-62.

14. Howard, D.M. Barlow, C.A., Welch, G.F. (2000) Vocal production and listener perception of trained girls and boys in the English Cathedral Choir. Proceedings of the $18^{\text {th }}$ international Seminar of the International Society for Music Education.

15. Howard, D.M., (1995). Variation of electrolaryngographically derived closed quotient for trained and untrained adult female singers. Journal of Voice, 9, 163-172.

16. Howard, D.M., (1998). Instrumental Voice Measurement: uses and limitations. In The Voice Clinic Handbook. (323-379) London: Whurr Publishers.

17. Huff-Gackle, L. (1985) The young adolescent female voice (ages 11-15): Classification, placement and development of tone. The Choral Journal, 25(8):15-18. 18. Kahane, J.C., (1978). A Morphological study of the human prepubertal and pubertal larynx. American Journal of Anatomy, 151, 11-20.

19. Rossiter, D.P., Howard, D.M., DeCosta, M., (1996). Voice development under training with and without the influence of real time visually presented biofeedback. Journal of the Acoustical Society of America, 99, 3253-3256. 
20. Tanner, J.M., (1978) Foetus into Man - Physical growth from conception to maturity. London: Open Books

21. Vaughan, V.C., Litt, I.F., (eds.) (1990) Child and Adolescent development Philadelphia: Saunders.

22. Weiss, D.A., (1950) The pubertal change of the human voice. Folia Phoniatrica, 2:125-159.

23. Internet www page at URL> http://www.laryngograph.com 


\section{Laryngeal development}

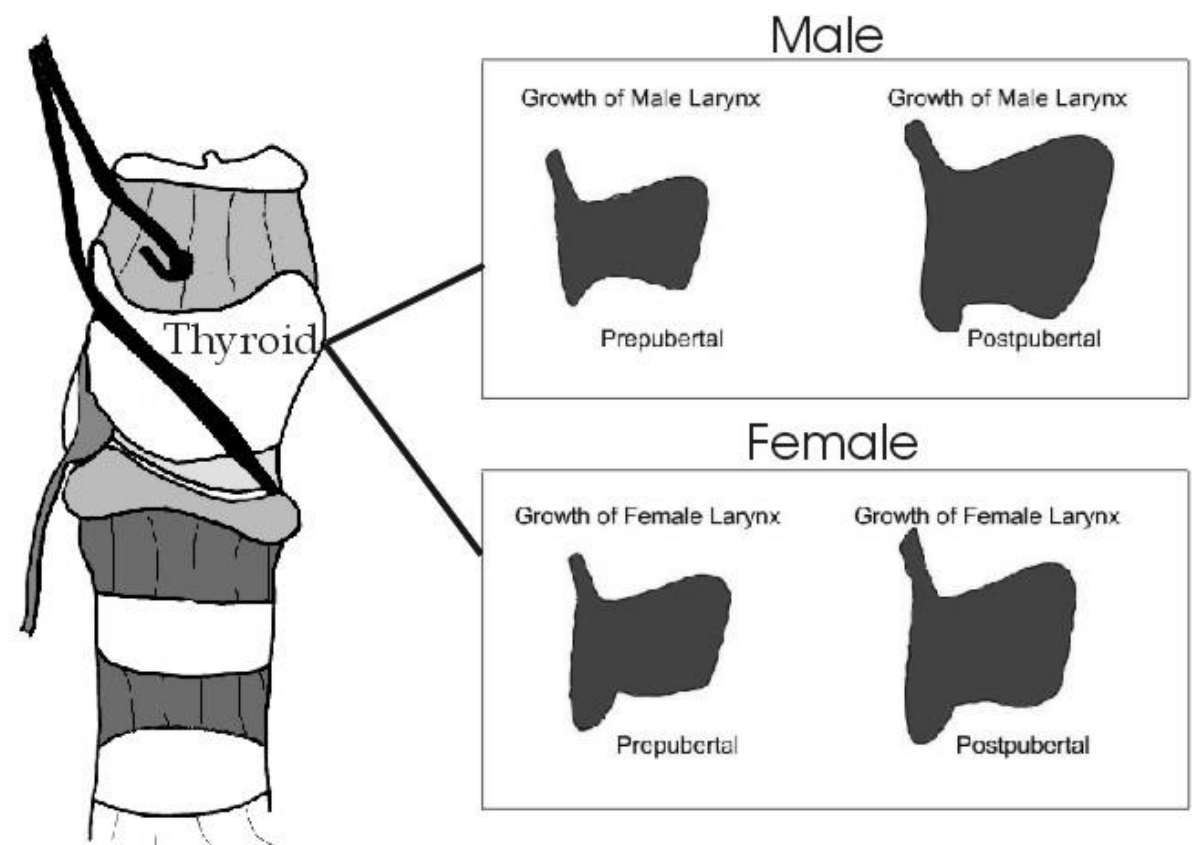

Figure 1 - Laryngeal growth during puberty (vertical cross section)

Derived from Kahane [18] 


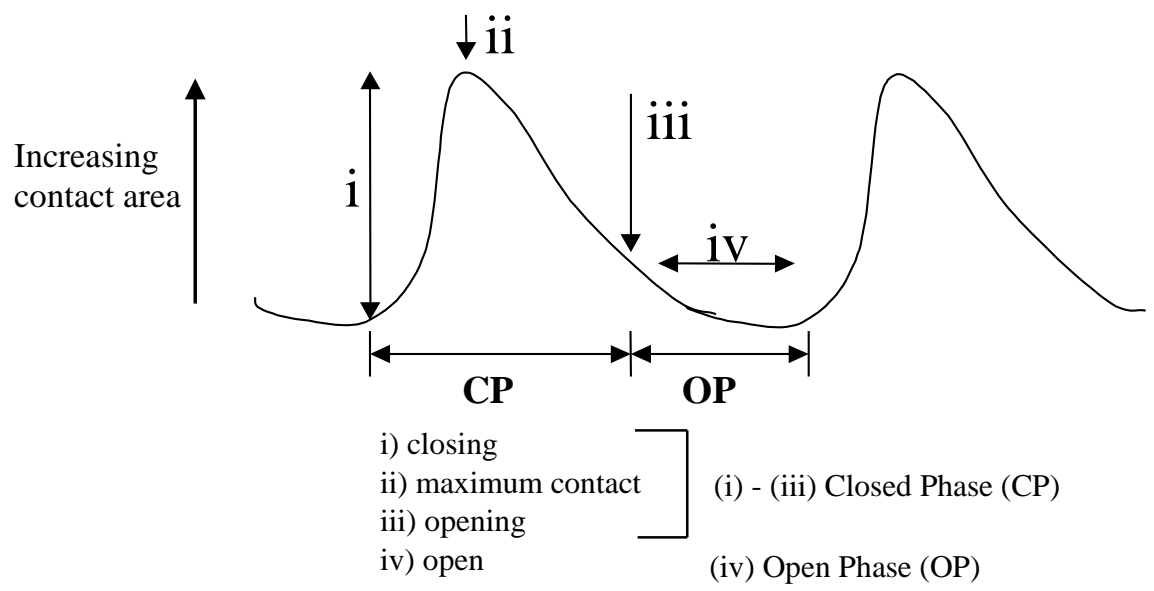

Figure 2 - Idealised electrolaryngograph output waveform showing closed and open phases (derived from [12]:206) 

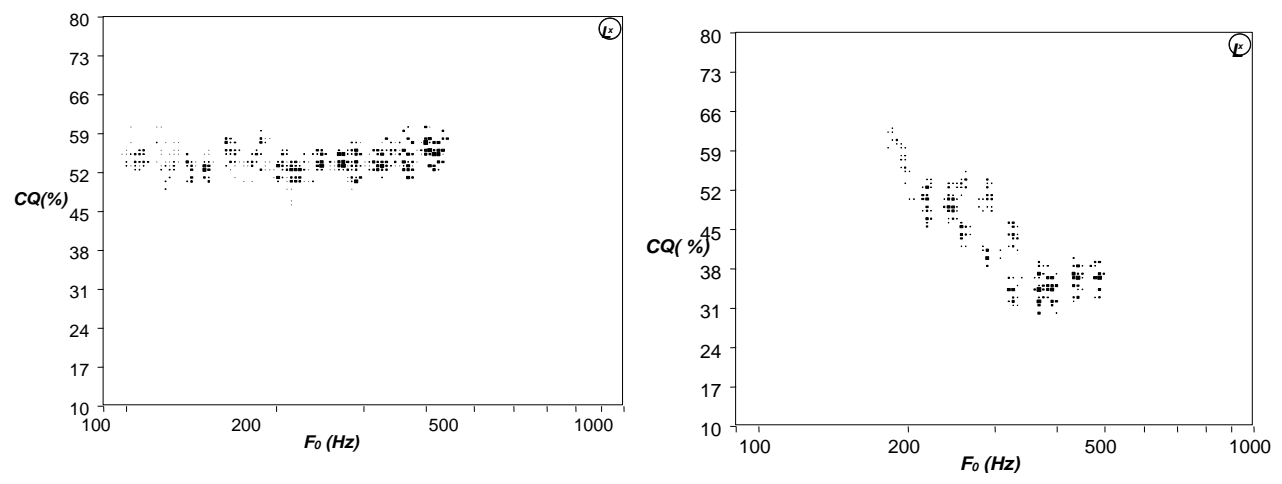

Figure 3 - examples of Qx plots. 18 year old male $(L)$ and 10 year old female $(R)$ 


\begin{tabular}{|c|c|c|}
\hline Classification & Pattern & Idealised Plot \\
\hline Group 1 & negative gradient slope throughout plot & \\
\hline Group 2 & horizontal (zero gradient) plot. \\
\hline Group 3 & $\begin{array}{c}\text { varying gradients (positive-negative positive } \\
\text { or negative-positive-negative). }\end{array}$ \\
\hline Group 4 & $\begin{array}{c}\text { initially negative then switching to positive } \\
\text { gradient (' } \mathrm{V} \text { ' shape). }\end{array}$ \\
\hline Group 5 & \begin{tabular}{c} 
positive gradient throughout plot \\
\hline
\end{tabular} \\
\hline
\end{tabular}

Table 1 - Vocal groupings according to slope of Qx plot. 
Male 12 and under - non singers Sample size 11

\begin{tabular}{|l|c|c|}
\hline Plot & $\begin{array}{c}\text { Number of } \\
\text { subjects }\end{array}$ & \% of group \\
\hline Group 1 & 6 & 54.5 \\
\hline Group 2 & 0 & 0 \\
\hline Group 3 & 2 & 18.2 \\
\hline Group 4 & 2 & 18.2 \\
\hline Group 5 & 1 & 9.1 \\
\hline
\end{tabular}

Female 12 and under - non singers Sample size 11

\begin{tabular}{|l|c|c|}
\hline Plot & $\begin{array}{c}\text { Number of } \\
\text { subjects }\end{array}$ & \% of group \\
\hline Group 1 & 8 & 72.7 \\
\hline Group 2 & 2 & 18.2 \\
\hline Group 3 & 1 & 9.1 \\
\hline Group 4 & 0 & 0 \\
\hline Group 5 & 0 & 0 \\
\hline
\end{tabular}

Table 2 - Distribution of Qx patterning for male and female non-singers age 12 and under 
Male 12 and under - singers

Sample size 20

\begin{tabular}{|l|c|c|}
\hline Plot & $\begin{array}{c}\text { Number of } \\
\text { subjects }\end{array}$ & $\begin{array}{l}\text { Mean length } \\
\text { of training } \\
\text { (yrs) }\end{array}$ \\
\hline Group 1 & 2 & 2.8 \\
\hline Group 2 & 6 & 1.8 \\
\hline Group 3 & 6 & 2.98 \\
\hline Group 4 & 2 & 3.2 \\
\hline Group 5 & 1 & $(1.5)$ \\
\hline
\end{tabular}

2 subjects no result
Female 12 and under - singers

Sample size 21

\begin{tabular}{|l|c|c|}
\hline Plot & $\begin{array}{c}\text { Number of } \\
\text { subjects }\end{array}$ & $\begin{array}{l}\text { Mean length } \\
\text { of training } \\
\text { (yrs) }\end{array}$ \\
\hline Group 1 & 5 & 2.7 \\
\hline Group 2 & 5 & 3.1 \\
\hline Group 3 & 5 & 3.3 \\
\hline Group 4 & 5 & 4.3 \\
\hline Group 5 & 1 & $(4.8)$ \\
\hline
\end{tabular}

Table 3 - Distribution of Qx patterning for male and female singers under 13 
Female 13 and over - Singers

Sample size 28

\begin{tabular}{|c|c|c|c|c|}
\hline Plot & $\begin{array}{c}\text { Number of } \\
\text { subjects }\end{array}$ & $\begin{array}{c}\text { Mean } \\
\text { age (yrs) }\end{array}$ & $\begin{array}{c}\text { Mean } \\
\text { speaking F0 } \\
(\mathrm{Hz})\end{array}$ & $\begin{array}{c}\text { Mean } \\
\text { length of } \\
\text { training } \\
(\mathrm{yrs})\end{array}$ \\
\hline Group 1 & 3 & 13.6 & 242 & 3.2 \\
\hline Group 2 & 3 & 15 & 240 & 2.8 \\
\hline Group 3 & 16 & 14.6 & 227 & 3.9 \\
\hline Group 4 & 8 & 14 & 240 & 4.4 \\
\hline Group 5 & 3 & 16 & 239 & 7.5 \\
\hline
\end{tabular}

Table 4 - Distribution of Qx plots for Female singers age 13-18 
Female 13 and over - Non singers

Sample size 16

\begin{tabular}{|c|c|c|c|c|}
\hline Plot & $\begin{array}{c}\text { Number of } \\
\text { subjects }\end{array}$ & $\begin{array}{c}\text { Mean age } \\
\text { (yrs) }\end{array}$ & $\begin{array}{c}\text { Mean } \\
\text { speaking } \\
\text { F0 (Hz) }\end{array}$ & $\begin{array}{c}\text { \% of } \\
\text { group }\end{array}$ \\
\hline Group 1 & 9 & 15 & 244 & 56.25 \\
\hline Group 2 & 5 & 14 & 235 & 31.25 \\
\hline Group 3 & 0 & $\mathrm{n} / \mathrm{a}$ & $\mathrm{n} / \mathrm{a}$ & 0 \\
\hline Group 4 & 1 & 16 & 190 & 6.25 \\
\hline Group 5 & 1 & 14 & 220 & 6.25 \\
\hline
\end{tabular}

Table 5 - Qx patterning of female non-singers aged 13-18 


\begin{tabular}{|c|c|c|}
\hline Classification & Pattern & Idealised plot \\
\hline Group 1 & $\begin{array}{c}\text { Subjects can exhibit any of the } \\
\text { plots I-V shown in table 1 above, } \\
\text { depending on training }\end{array}$ & See table 1 \\
\hline Group 2 & Positive/negative (inverted 'V') & \\
\hline Group 3 & Negative/horizontal slope & \\
\hline Group 4 & Horizontal slope & \\
\hline
\end{tabular}

Table 6 - Vocal groupings of adolescent males according to slope of Qx plot. 
Male subjects 13 \& over

Sample size 20

\begin{tabular}{|c|c|c|c|c|c|}
\hline Plot & $\begin{array}{c}\text { Number of } \\
\text { subjects }\end{array}$ & $\begin{array}{c}\text { Mean age } \\
(\mathrm{yrs})\end{array}$ & $\begin{array}{c}\text { Mean } \\
\text { speaking } \\
\mathrm{F} 0(\mathrm{~Hz})\end{array}$ & $\begin{array}{c}\text { Mean } \\
\text { length of } \\
\text { training } \\
\text { (yrs) }\end{array}$ & $\%$ of group \\
\hline Group 1 & 3 & 13.6 & 171 & 2 & 15 \\
\hline Group 2 & 4 & 15.5 & 140.5 & 2 & 20 \\
\hline Group 3 & 2 & 15 & 122 & 5.5 & 10 \\
\hline Group 4 & 11 & 15.8 & 138 & 3.8 & 55 \\
\hline
\end{tabular}

Table 7 - Qx patterning of male subjects aged 13+ 


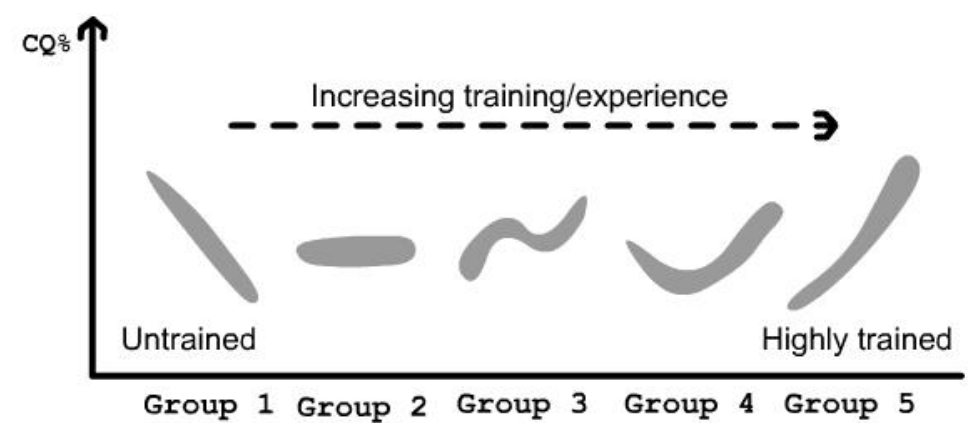

Figure 4 - Idealised Qx plots for prepubertal Male and all child/adolescent

Female singers. 


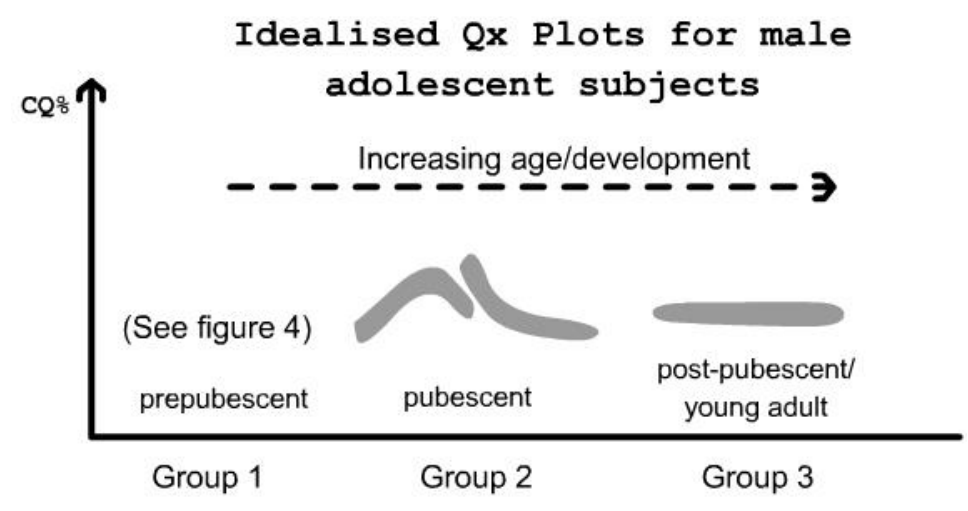

Figure 5 - Idealised Qx plots for male singers from pre-pubescent to post-

pubescent 


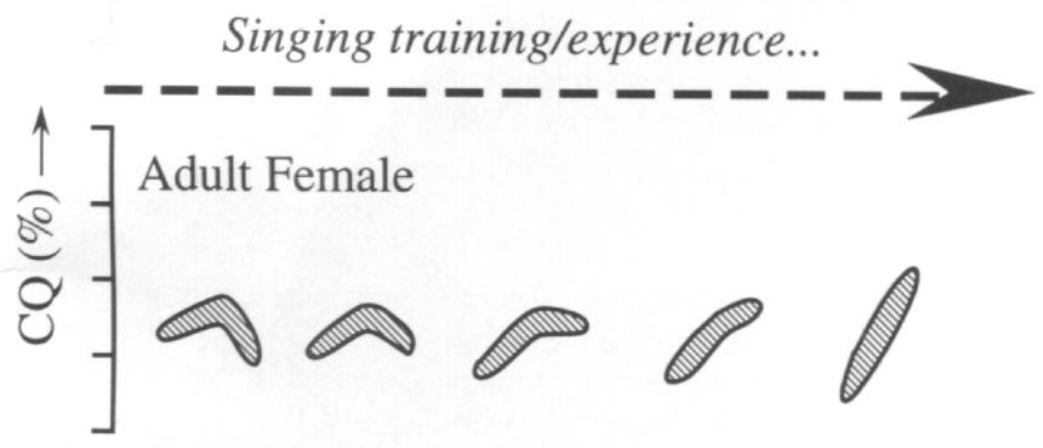

Figure 6 - Qx plot patterning for Adult Female singers [16:171] 